\section{To What Extent Does}

\section{Poor Health Precede Welfare?}

\author{
Evan Morris, $\mathrm{MSc}^{1}$ \\ David Rosenbluth, $\mathrm{PhD}^{2}$ \\ Doug Scott, $\mathrm{MA}^{3}$ \\ Trish Livingstone, $\mathrm{MA}^{4}$ \\ Lisa Lix, $\mathrm{PhD}^{5}$ \\ Mary McNutt, $\mathrm{MSc}^{6}$ \\ Felecia Watson, $\mathrm{MSc}^{7}$
}

$\mathrm{P}$ eople with low income have more health problems than those with higher income, ${ }^{1-8}$ and welfare recipients have a lower health status than both the working poor and those who are not poor. ${ }^{9-12}$ One explanation for this pattern is that income level affects health status through a number of intermediate variables, such as the ability to afford medical services, quality of housing, accessibility of health services, lifestyle behaviours, and psychosocial factors. ${ }^{13} \mathrm{~A}$ second explanation, which we investigate in this paper, is the drift hypothesis. The drift hypothesis states that a deterioration in health status can reduce the income level of an individual. ${ }^{14}$

In the case of welfare recipients, both processes may be taking place. Individuals who become poor may become less healthy as a result of their poverty, while a drop in health status may result in individuals leaving the workforce and receiving welfare. Measuring the relative strength of these processes is important as it will affect policies that aim to help individuals move from welfare to the workforce.

The strength of the effect of a drop in health status resulting in downward social mobility is often assumed to be small. ${ }^{15,16}$ This assumption may be true for individuals in higher income levels, but the effect may be substantial among lower-income individuals who move to welfare. Most research in this area has examined the relationship between health status and income among all income groups in a society. Given the very significant differences in health status between welfare recipients and the working poor, the direction and strength of the relationship between income and health may be different for welfare recipients than for individuals in higher income groups. Many studies show that the relationship between income and health status is not a linear one. There are often slight differences in health status among the higher income quintiles, but marked differences in health status between the lowest two income quintiles. ${ }^{17-21}$ Individuals in higher income brackets may have greater economic resources to provide income during a longterm illness. To shed light on the relationship between the health and income of welfare recipients, we have to determine why individuals move to welfare.

The most common reasons for adults to receive welfare are: unemployment due to 
lack of work; inability to work due to a chronic illness or disability; and inability to work for other reasons, such as looking after young children. Poor health can cause unemployment directly, when an accident or disabling illness causes an individual to leave their employment or to work reduced hours. ${ }^{22,23}$ In other cases, a healthy person may leave his or her job in order to take care of a family member who suffers from an illness or disability. ${ }^{24,25}$

Many surveys of welfare recipients indicate that poor health is a major barrier to entering the workforce. ${ }^{26}$ However, crosssectional studies such as these cannot tell us to what extent a drop in health status resulted in individuals receiving welfare. It is necessary to examine the same population over a period of time in order to determine if a move to welfare preceded an individual's change in health status, or vice versa. Most of the work analyzing the health problems of welfare recipients has concentrated on mental health problems and substance use. Health policy recommendations require more detailed information on the types of health problems that may have resulted in individuals leaving the workforce and moving to welfare.

In this paper, we examine the extent to which health status deteriorated before individuals received social assistance.

\section{METHODS}

The study population consisted of all Saskatchewan adults (18 years and over) who became social assistance recipients during the period July 1997 to January 2000, and who had been continuously off social assistance for one year followed by at least six months on social assistance. The study population consisted of 2,652 adults, and included 1,423 men and 1,229 women. This study population does not include the following social assistance recipients: assisted adoptions; wards of the state; and those in group homes, special care homes or supervised accommodations. These individuals make up approximately $12 \%$ of all individuals receiving social assistance.

Health status can be measured in various ways, including self-reporting of general health status, self-reporting of specific measures such as the number and severity of symptoms, and administrative data that record diagnoses and the number of medical services used. While several studies have found a close correspondence among the various measures of health status, ${ }^{27-32}$ each measure has different strengths and weaknesses. When the health of workers and non-workers is compared, there is some evidence that non-workers tend to erroneously classify their health as poor. ${ }^{33}$ If we were to compare the self-reported health status of individuals before and after they move to welfare, any decrease in health status could be due to this reporting bias. Our use of physician services as a proxy for health status eliminates this bias.

Saskatchewan Health's administrative databases were used to compile physician utilization data for the study. Saskatchewan Health maintains a Personal Registry System, which is a registry of all residents eligible for Saskatchewan health services. The registry contains demographic information on residents, as well as information specifying whether or not the individual is receiving supplementary health coverage as a recipient of social assistance. Through the use of this registry, it was possible to identify all individuals who had been on social assistance health coverage for 6 months after being on regular health coverage for a year.

Registered Indians were excluded from this study, since it was not possible to determine from the Saskatchewan Health databases which Registered Indians were on social assistance. In March of 2000 , Registered Indians made up 31\% of the families on social assistance.

Saskatchewan Health also maintains a physician billing claims database. Since all fee-for-service physicians submit billing claims, and most salaried physicians submit parallel "shadow" billing claims, this database captured most of the physician services in the province. Records in this database included the date of service and the International Classification of Disease, $9^{\text {th }}$ revision (ICD-9) diagnostic code. A visit to a physician may include more than one service.

By using a personal health number assigned to individuals whose service records are included in Saskatchewan Health's administrative database, it was possible to monitor person-specific physician service utilization across the period of the study. It was also possible to determine whether an individual was receiving supplementary health benefits as a result of being on social assistance at any period of time. Approval for data access was received from the Data Access Review Committee of Saskatchewan Health.

Physician service use was examined prior to and after an individual became a social assistance recipient. The data were analyzed using descriptive statistics and physician utilization rates. These health data are based on the population of individuals who fit the study criteria, not on samples. As a result, statistical tests do not need to be carried out in order to determine if any changes are significant.

Physician service use was measured during three time intervals: Period $1-$ First 6 months (not on social assistance); Period 2 - Second 6 months (not on social assistance); Period 3 - Third 6 months (receiving social assistance).

Since individuals commenced their receipt of welfare at different times during the study period, the 18-month interval will cover different start and end dates for each individual. The total number of physician services was calculated for each 6-month interval. Changes in the number of services for people in the study were compared to changes in the number of services for the entire Saskatchewan population during the same period. This was done to ensure that any changes in the use of physician services by the study population were not due to factors affecting the entire Saskatchewan population.

We calculated the number and proportion of individuals who had increased their use of physician services between Period 1 and Period 3. An individual was considered to have an increased level of services if the total number of services was greater in Period 3 than in Period 1.

Some physician services are not for illnesses, but for normal conditions that individuals may pass through during their lifetimes. The largest number of such services was due to pregnancy and childbirth, which made up approximately $10 \%$ of all services for the study population. In order to estimate changes in physician use due to health problems, the above calculation was carried out with all pregnancy and childbirth services removed.

Physician service rates were calculated for all those individuals who had under- 
TABLE I

Change in Physician Services of Individuals Between Period 1 and Period 3 - Pregnancy and Childbirth Services Removed

\begin{tabular}{lccc} 
Service Utilization & Men & Women & Both \\
& $\mathbf{n}(\%)$ & $\mathbf{n}(\%)$ & $1310(49)$ \\
Increased & $681(48)$ & $629(51)$ & $467(18)$ \\
No Change & $329(23)$ & $138(11)$ & $875(33)$ \\
Decreased & $413(29)$ & $462(38)$ & $2652(100)$ \\
Total & $1423(100)$ & $1229(100)$ & \\
\hline
\end{tabular}

TABLE II

Physician Services and Service Rates Over Time (Services per Person-year) for Individuals Whose Service Rates Increased Between Periods 1 and 3

\begin{tabular}{|c|c|c|c|}
\hline & Men & Women & Both \\
\hline \multicolumn{4}{|l|}{ Services } \\
\hline Period 1: Regular Coverage & 1695 & 2764 & 4459 \\
\hline Period 2: Regular Coverage & 4107 & 5419 & 9526 \\
\hline Period 3: Social Assistance Coverage & 6672 & 7431 & 14,103 \\
\hline \multicolumn{4}{|l|}{ Service rates per person-year } \\
\hline Period 1: Regular Coverage & 5.0 & 8.8 & 6.8 \\
\hline Period 2: Regular Coverage & 12.0 & 17.2 & 14.6 \\
\hline Period 3: Social Assistance Coverage & 19.5 & 23.6 & 21.6 \\
\hline
\end{tabular}

\section{TABLE III}

Increase in Physician Services for Selected ICD-9 Chapters for Individuals Whose Service Rates Increased Between Periods 1 and 3

ICD-9 Chapter
Men
Mental disorders
Injury and poisoning
Musculoskeletal
Symptoms, Signs
Respiratory system
Nervous system
All services for men
Women
Mental disorders
Genitourinary
Respiratory system
Musculoskeletal
Injury and poisoning
Symptoms, Signs
All services for women

\begin{tabular}{rrr}
\multicolumn{3}{c}{ Number of Services } \\
\hline Period 1 & Period 2 & Period 3 \\
& & \\
204 & 553 & 1019 \\
195 & 428 & 716 \\
187 & 356 & 574 \\
101 & 267 & 527 \\
157 & 359 & 496 \\
94 & 255 & 430 \\
1695 & 4107 & 6672 \\
& & \\
346 & 748 & 1096 \\
224 & 523 & 762 \\
330 & 465 & 592 \\
214 & 315 & 456 \\
179 & 310 & 422 \\
167 & 274 & 325 \\
2764 & 5419 & 7431
\end{tabular}

$\%$ Increase

$400 \%$
$267 \%$
$207 \%$
$422 \%$
$216 \%$
$357 \%$

$357 \%$

$217 \%$

$240 \%$

$240 \%$
$79 \%$

$113 \%$

$136 \%$

$95 \%$

* Note: Data are only displayed for the six ICD-9 diagnostic chapters with the highest number of physician services in Period 3.

gone an increase in physician services between Period 1 and Period 3. Utilization rates were calculated as the number of services per person-year for each of the three time periods. Utilization rates were also calculated for each time period using the diagnostic categories of the International Classification of Diseases, $9^{\text {th }}$ Revision (ICD-9) classification system. The first 17 major categories or chapters of the ICD-9 classification system deal with illnesses. Preventive services are restricted to a chapter of supplementary codes. The calculation of service rates by chapter allowed us to isolate the effect of preventive services, and permitted us to determine which types of illness increased over time for those individuals who moved to social assistance.

\section{RESULTS}

For the 2,652 adults in the study population, the total number of physician services increased during each of the three 6-month intervals. The total number of services was 42\% higher in Period 3 than in Period 1. In contrast, the number of physician services used in Saskatchewan by all residents only increased by $4 \%$ during the period $1997 / 98$ to $1999 / 2000 . .^{34}$

A total of 1,310 individuals (49\%) had increases in physician services from the first to the third six-month period (Table I). This population consisted of 681 men and 629 women.

For the 1,310 individuals who had service increases, the total number of services increased from 4,459 in Period 1 to 14,103 in Period 3 (Table II). Fifty-three percent of this total increase took place between Periods 1 and 2. For those individuals who had service increases between Periods 1 and 3, physician services increased by $216 \%$. Men had a greater increase in services (294\%) than women (169\%).

Among men, physician services for mental disorders increased by $400 \%$ between Periods 1 and 3 (Table III). There were also large percentage increases in the ICD-9 chapters of Symptoms and Signs (422\%), diseases of the nervous system (357\%), and injury and poisoning (267\%). Among women, services for diseases of the genitourinary system increased by $240 \%$, and services for mental disorders increased by $217 \%$.

Individuals moving to social assistance also increased their use of preventive services. Both men and women had large increases in services for general examinations and for consultations without a specific complaint or sickness. The number of these physician services for women increased from 193 in Period 1 to 542 in Period 3, an increase of $181 \%$. The increase for men was from 85 to 340 services, or $300 \%$. For women, $79 \%$ of this total increase occurred between period 1 and period 2 . For men, only $33 \%$ of the total increase occurred between period 1 and 2 .

Among men whose services increased between Periods 1 and 3, the highest proportion of physician services in Period 3 was for mental disorders. These comprised $15 \%$ of the 6,672 physician services reported in Period 3. This was followed by injury and poisoning (11\%) and diseases of the musculoskeletal system (9\%). The highest proportion of services for women on social assistance was for mental disorders (15\%), followed by genitourinary $(10 \%)$ and diseases of the musculoskeletal system (6\%). Preventive services (general examinations and consultations without a specific complaint or sickness) made up $5 \%$ of all services for men and $7 \%$ of all services for women during Period 3. This is similar to the percentages for Period 1 .

\section{DISCUSSION}

Almost one half (49\%) of adults in the study population had increases in physician service use between Periods 1 and 3 . 
This increase in physician service use cannot be explained by trends affecting the entire population since the number of physician services among the Saskatchewan population was stable during the entire study period. The increased use of physician services for health problems indicates that deteriorating health may have been a contributing factor leading to welfare for some of these individuals. This increase in physician services use cannot be explained by a greater use of preventive services, since these comprised only a small proportion of all services.

For those individuals who had an increase in physician services, $53 \%$ of the increase in service use occurred during the 12 months prior to receiving social assistance. This is consistent with the drift hypothesis, where a drop in health status precedes and is a cause of downward social mobility and a drop in income.

The use of health services as a proxy for health status has some limitations. The number of physician services an individual uses does not necessarily reflect the severity of an illness or other health problem. Other types of data are required to measure the severity of health problems. One source of such data is a survey of social assistance recipients carried out for the Department of Social Services in 2001. "Almost onethird $(31 \%)$ of respondents report longterm physical problems, and nearly 1 respondent in 10 (9\%) has long-term mental health problems. Forty percent (40\%) reported feeling anxious, irritable, or depressed to such an extent that their activities are limited by these feelings." ${ }^{35}$

A move to social assistance often indicates a large drop in income. However, the income level for an individual may have been falling for quite some time, and we have no way of knowing for which individuals this was the case. Such individuals may have been unemployed and living on employment insurance prior to receiving social assistance. They may have suffered a drop in health status after losing their job, but before receiving social assistance. In this case, a drop in income may have resulted in a lower health status, but this would have occurred prior to their receiving social assistance. For such individuals, downward social mobility may have resulted in poorer health status through one or more intervening variables.
For other individuals, a drop in health status may have resulted in their shifting to part-time work. If the health status of these individuals continued to deteriorate, they may have been forced to leave the workforce entirely and go on social assistance. In this case, a drop in health status would have been the cause of a drop in income. Such a situation is consistent with the downward drift hypothesis, but would not be reflected in our data, as the drop in health status may have occurred well before the 1-year period prior to receiving social assistance.

Single adults are more likely to be affected economically by poor health than adults in dual-earner households. If one individual in a dual-earner household lost their job due to poor health, the earnings of the second earner would normally be higher than the cut-off level for social assistance. Loss of income by a single earner may make them eligible for social assistance. This may partially explain why single persons and single-parent families make up such a large proportion $(90 \%)$ of the Saskatchewan social assistance caseload. Also, a drop in health status may have a greater economic impact on individuals at lower income levels, since they are less likely to have economic resources such as private or employer-sponsored insurance programs that provide income during periods of long-term illness or disability.

Canadians who lose their jobs due to ill health have longer unemployment spells than other workers. ${ }^{36}$ Similarly, adults who go onto social assistance due to ill health may be more likely to remain on social assistance than those who are not sick. Their poor health status can also act as a barrier to returning to the workforce.

Factors such as an improvement in the job market or further training may reduce the social assistance rolls, but will have a minimal impact on individuals who have had a loss of income due to deteriorating health. Programs that allow ill or disabled workers to work shorter hours and have flexible schedules may increase the level of job retention after illness, and reduce the number of individuals who lose their jobs and move to welfare. Welfare-to-work initiatives need to deal with the health problems faced by many social assistance recipients. If a decline in health status results in downward social mobility, then it seems reasonable to expect that upward mobility will also occur when health status improves. If the health status of social assistance recipients improves, these healthier individuals may return to the workforce and increase their incomes.

\section{REFERENCES}

1. Lynch J, Smith GD, Harper S, Hillemeier M, Ross N, Kaplan GA, Wolfson M. Is income inequality a determinant of population health: Part 1. A systematic review. The Milbank $Q$ 2004,82(1):5-99.

2. Statistics Canada. General Social Survey Analysis Series, Health and Social Support, 1985. Ottawa, ON: Supply and Services Canada, 1987.

3. Health and Welfare Canada. Active Health Report - Perspectives on Canada's Health Promotion Survey 1985. Ottawa, ON: Supply and Services Canada, 1987.

4. Health and Welfare Canada. Canada's Health Promotion Survey 1990, Technical Report. Ottawa, ON: Supply and Services Canada, 1993.

5. Minister of Public Works and Government Services Canada. National Forum on Health: What Determines Health? Ottawa, 1996.

6. Federal, Provincial and Territorial Advisory Committee on Population Health: Minister of Public Works and Government Services, Canada. Toward a Healthy Future: Second Report on the Health of Canadians. Ottawa, 1999.

7. Glazier RH, Bradley EM, Gilbert JE, Rothman $\mathrm{L}$. The nature of increased hospital use in poor neighbourhoods: Findings from a Canadian city. Can J Public Health 2000;91:268-73.

8. Byrne C, Browne G, Roberts J, Ewart B, Schuster M, Underwood J, et al. Surviving social assistance: 12-month prevalence of depression in sole-support parents receiving social assistance. CMAJ 1998;158:881-88.

9. Kozyrskyj A, Mustard S, Derksen S. Considering the Health Care Needs of Children Living in Households Receiving Social Assistance in Manitoba. Winnipeg, MB: Manitoba Centre for Health Policy and Evaluation, December 2000.

10. Williamson D, Fast J. Poverty status, health behaviours and health: Implications for social assistance and health care policy. Canadian Public Policy/Analyse de Politiques 1998;24(1):1-25.

11. Saskatchewan Health and Saskatchewan Social Services. Monitoring the Effects of Family Health Benefits for Low-Income Families in Saskatchewan. Regina, SK: Government of Saskatchewan, 2001. Available on-line at: www.dcre.gov.sk.ca/publications/pdfs/FHB.pdf (Accessed April 2, 2005).

12. Vozoris N, Tarasuk V. The health of Canadians on welfare. Can J Public Health 2004;95(2):11520.

13. Gordon D, Shaw M, Dorling D, Davey Smith G (Eds.). Inequalities in Health: The Evidence. Bristol, UK: Policy Press, 1999.

14. Harvey J, Miles DL, Rushing WA. The relationship between social class and functional status: A new look at the drift hypothesis. J Health Soc Behav 1976;17(3):194-204

15. Blane D, Smith GD, Bartley M. Social selection, what does it contribute to social class differences in health? Sociol Health Illness 1993;15(1):1-15.

16. Hertzman C. The case for an early childhood development strategy. Isuma 2000;1(2):11-18.

17. Mustard CA, Derksen S, Berthelot J-M, Wolfson $\mathrm{M}$, Roos LL. Age-specific education and income gradients in morbidity and mortality in a Canadian province. Soc Sci Med 1997;45(3):38397. 
18. Ecob R, Smith GD. Income and health: What is the nature of the relationship? Soc Sci Med 1999;48:693-705.

19. Backlund E, Sorlie PD, Johnson NJ. A comparison of the relationships of education and income with mortality: The National Longitudinal Mortality Study. Soc Sci Med 1999;49:1373-84.

20. Ross D, Roberts P, Scott K. Family income and child well-being. Isuma 2000;1(2):51-54.

21. Wilkins R, Houle C, Berthelot J, Ross N. The changing health status of Canada's children. Isuma 2000;1(2):57-63.

22. Christofides LN, Stengos T, Swidinsky R. Welfare participation and labour market behaviour in Canada. Can $J$ Economics 1997;30(3):595-621.

23. Arrow JO. Estimating the influence of health as a risk factor on unemployment: A survival analysis of employment durations for workers surveyed in the German Socio-Economic Panel (1984-1990). Soc Sci Med 1996;42(12):1651-59.

24. Smith LA, Romero D, Wood PR, Wampler NS, Chavkin W, Wise PH. Employment barriers among welfare recipients and applicants with chronically ill children. Am J Public Health 2002;92(9):1453-57.

25. Wise PH, Wampler NS, Chavkin W, Romero D. Chronic illness among poor children enrolled in the Temporary Assistance for Needy Families program. Am J Public Health 2002;92(9):145861.

26. Thériault L, Rosenbluth D. Moving from welfare to work: Saskatchewan Social Assistance applicants in perspective. Prairie Forum 2002;27(1):59-82.

27. Baker M, Stabile M, Deri C. What do selfreported, objective measures of health measure? NBER Working Paper No. W8419; 2001.

28. Butler JS, Burkhauser RV, Mitchell JM, Pincus TP. Measurement error in self-reported health variables. Rev Economics Statistics 1987;69(4):644-50
29. Mossey JM, Roos LL. Using insurance claims to measure health status: The Illness Scale. J Chron Dis 1987;40(Suppl. 1):41S-54S.

30. Pope GC. Medical conditions, health status, and health services utilization. Health Services Res 1988;22(6):857-77.

31. Roos NP, Carrière KC, Friesen D. Factors influencing the frequency of visits by hypertensive patients to primary care physicians in Winnipeg. CMAJ 1998;159(7):777-83.

32. Stineman MG, Ross RN, Maislin G, Iezzoni L. Estimating health-related quality of life in populations through cross-sectional surveys. Medical Care 2004;42(6):569-78

33. Bound J. Self-reported versus objective measures of health in retirement models. J Human Res 1991;26(1):106-38.

34. Saskatchewan Health. Medical Services and Health Registration Branch Annual Statistical
Reports, 1996-97 to 1999-2000. Regina, SK: Government of Saskatchewan.

35. Saskatchewan Social Services. Barriers to employment: A survey of social assistance applicants. Regina: Government of Saskatchewan, 2001. Available on-line at: www.dcre.gov.sk.ca/ publications/ClientBarrierSurvey/SAPbarrierpublic report3.htm (Accessed April 2, 2005)

36. Stewart JM. The impact of health status on the duration of unemployment spells and the implications for studies of the impact of unemployment on health status. I Health Economics 2001;20:781-96.

Received: February 24, 2004

Revisions requested: April 16, 2004 \& August 24, 2004

Revised mss: June 7, 2004 \& October 26, 2004

Accepted: December 10, 2004

\section{RÉSUMÉ}

Contexte : On sait que les bénéficiaires de l'aide sociale ont davantage de problèmes de santé que les personnes dont les revenus sont plus élevés. Dans cet article, nous avons estimé la proportion de bénéficiaires qui ont touché des prestations sociales après une aggravation de leur état de santé.

Méthode : La population à l'étude se composait d'adultes de la Saskatchewan n'ayant touché aucune prestation sociale pendant 12 mois consécutifs, puis ayant reçu des prestations pendant 6 mois. Nous avons mesuré leur état de santé d'après leurs visites chez le médecin, en examinant les changements dans les taux de visite sur une période de 18 mois

Résultats : Quarante-neuf p. cent des sujets de la population à l'étude avaient eu recours plus souvent aux services d'un médecin sur l'ensemble de la période de 18 mois. Pour ces personnes, $53 \%$ de l'utilisation accrue des services avait eu lieu au cours des 12 mois précédant leur entrée dans les rangs des assistés sociaux.

Conclusions : La détérioration de la santé, mesurée selon l'utilisation accrue des services d'un médecin, semble être un facteur qui précède le recours à l'aide sociale pour beaucoup de gens. Les mesures pour améliorer l'état de santé pourraient donc être un moyen d'aider les gens à ne pas dépendre de l'aide sociale.

\section{Canadian Hepatitis C Information Centre}

\section{Centre canadien d'information sur I'hépatite C}

Get the facts. Informez-vous.

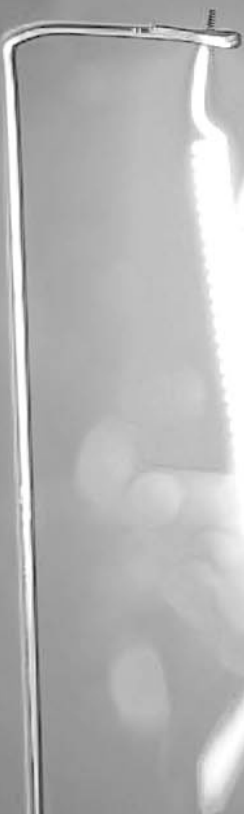

